\title{
Effect of Plasma, RF, and RIE Treatments on Properties of Double-Sided High Voltage Solar Cells with Vertically Aligned p-n Junctions
}

\author{
Mykola O. Semenenko, ${ }^{1,2}$ Mykhailo G. Dusheiko, ${ }^{3}$ Sergiy V. Mamykin, ${ }^{2}$ Valeriy O. Ganus, \\ Mykhailo V. Kirichenko, ${ }^{4}$ Roman V. Zaitsev, ${ }^{4}$ Mykola M. Kharchenko, ${ }^{4}$ and N. I. Klyui ${ }^{1,2}$ \\ ${ }^{1}$ College of Physics, Jilin University, Changchun 130012, China \\ ${ }^{2} V$. Lashkaryov Institute of Semiconductor Physics of the NAS of Ukraine, 41 Nauky Pr., Kyiv 03680, Ukraine \\ ${ }^{3}$ National Technical University of Ukraine "KPI", 37 Pr. Peremohy, Kyiv, Ukraine \\ ${ }^{4}$ National Technical University "Kharkiv Polytechnic Institute", 21 Frunze St., Kharkiv 61002, Ukraine \\ Correspondence should be addressed to N. I. Klyui; klyuini@ukr.net
}

Received 4 July 2016; Accepted 31 August 2016

Academic Editor: Sergey Varlamov

Copyright (C) 2016 Mykola O. Semenenko et al. This is an open access article distributed under the Creative Commons Attribution License, which permits unrestricted use, distribution, and reproduction in any medium, provided the original work is properly cited.

Si-based solar cells with vertically aligned p-n junctions operating at high voltage were designed and fabricated. The plasma treatments and antireflection coating deposition on the working surfaces of both single- and multijunction cells were made using the special holders. It was shown that additional treatment of solar cells in argon plasma prior to hydrogen plasma treatment and deposition of diamond-like carbon antireflection films led to the improvement of the cell efficiency by up to $60 \%$. Radio frequency waves support plasma generation and improve photoelectric conversion mainly due to reduction of internal stresses at the interfaces. Application of reactive ion etching technique removes the broken layer, reduces elastic strain in the wafer, decreases recombination of charge carriers in the bulk, and provides cell efficiency increase by up to ten times.

\section{Introduction}

The transition of energy generation from fossil fuels to renewable sources, which are mainly based on solar energy converters, is a great aim for oil independent society [1]. Multijunction (MJ) Si-based solar cells (Si-SCs) are much more efficient in light irradiation conversion due to the possibility of providing the output voltage 10-40 times higher [2-4] than that given by similar SCs having a single junction (SJ). Such an efficiency enhancement can be achieved because higher open-circuit voltage $U_{\mathrm{OC}}$ can be more efficiently converted to AC-voltage and transmitted to household devices with smaller energy losses. Apart from this, Si-SCs that can be designed in diode configuration with p-n junctions oriented normally with respect to the illuminated surface and parallel to light propagation (vertically aligned $p-n$ junction, VA) would efficiently produce the electricity less dependent on a spectrum of light [5]. Moreover, the above orientation of $\mathrm{p}-\mathrm{n}$ junction makes it independent of the light absorber thickness [6]. Thus, VA geometry enables high performance to be realized even with low-quality, cost-effective materials at the thicknesses equal to or less than the minority charge carrier diffusion length of the material as it was discussed in [7].

On the other hand, light losses due to parasitic reflection also should be discussed. One of the candidates for protective and antireflection coating (ARC) for SCs is a diamondlike carbon film (DLCFs) [8-10]. Generally DLC ARCs are obtained by the plasma-enhanced chemical vapor deposition (PECVD) technique. The optical and mechanical properties of DLCFs can be changed over a wide range by varying the conditions via PECVD. Moreover, multilayered ARCs with gradient refractive index distribution can be obtained in a single deposition process when surfaces of films in stack are not oxidized. The key problems occurring in amorphous 
films deposition, for example, ARC, can be formulated as follows. There is the presence of initial significant internal mechanical stresses as well as dangling bonds that results in defect density contribution to impairment of transport properties of ARC. An efficient way to overcome this problem is dangling bond passivation with small-diameter atoms, for example, by adding atomic hydrogen to the structure. Due to its high reaction activity, hydrogen attaches itself to the dangling bonds which results in the significant reduction of dangling bonds concentration [1]. In addition, atomic nitrogen in DLCFs acts as a donor impurity and improves conductivity of DLCFs [11]. As it was noticed in [12, 13], DLCFs can essentially improve SCs degradation stability under ionizing radiation. Therefore, in this work we design double-sided Si-based SCs with vertically aligned multi-p$\mathrm{n}$ junctions operating at high voltage as well as study the effect of radio frequency (RF) stimulated plasma treatment and DLCF deposition on improvement of SC efficiency.

\section{Measurements and Setup}

VA-SJ-p-n-Si-SCs were design from (100) oriented borondoped $\mathrm{p}-\mathrm{Si}$ wafers in the typical $\mathrm{n}^{+}-\mathrm{p}-\mathrm{p}^{+}$configuration [2]. The thickness of $\mathrm{n}^{+}$-region was less than $1 \mu \mathrm{m}$. The $\mathrm{p}^{+}-$ and $\mathrm{n}^{+}$-regions were formed by diffusion of aluminum and phosphorus, respectively. The resistivity of p-region was $1 \mathrm{ohm} \times \mathrm{cm}$. To form the Ag contacts, an electrode collector was formed on the $\mathrm{n}^{+}$-Si wafer region by the thermal-vacuum condensation method with subsequent vacuum annealing and $\mathrm{Al} / \mathrm{Ag}$ composite on the $\mathrm{p}^{+}$-Si side in the same way. The surface area and sample thickness were $0.03 \mathrm{~cm}^{2}$ and $300 \mu \mathrm{m}$, respectively. The assembly of prepared VA-MJ-p-n-Si-SCs module was done by composing together 25 stripes of samples followed with pressing. The $100 \mu \mathrm{m}$ thick layer of welding paste was placed at both sides of the single SC. Then the stacks were heated for $5 \mathrm{~min}$ at $300^{\circ} \mathrm{C}$ in a vacuum chamber under pressure. Cooling down and cutting were performed in the vacuum chamber. Then the modules were polished for $10 \mathrm{~min}$ at $25^{\circ} \mathrm{C}$ and at the final stage chemically etched during few minutes with subsequent rinsing in an ultrasonic bath with alcohol. The mechanically operated machines with diamond powder (grain size from $1 \mu \mathrm{m}$ to $10 \mu \mathrm{m}$ ) were used for polishing. To study the $I-U$ characteristics and provide the plasma treatments for VA-SJ-p-n-Si-SCs, a special holder for fixation of single SC was constructed (see Figure 1).

This holder consisted of a flat copper foil base 1 and beryllium-copper springs 2 soldered to the base. The SJ-SC 5 was mounted facing up on the insulating base 3 and fixed by springs 2 for contacting both SJ-SCs sides. Since the (outer) Al- and Ag-based contacts to SJ-SC were deposited in a vacuum, this design improved the electrical contact (in addition to mechanical fixation). This allowed us to use the holder not only for the plasma treatments of SJ-SCs but also for manipulations during $I-U$ measurements outside the vacuum chamber as well.

The surface morphology was studied using a Shimadzu HMV-2000 microscope with 100x and 500x magnification.

DLCFs were deposited by PECVD technique. Plasma was generated with RF stimulation $(13.56 \mathrm{MHz})$. The beam

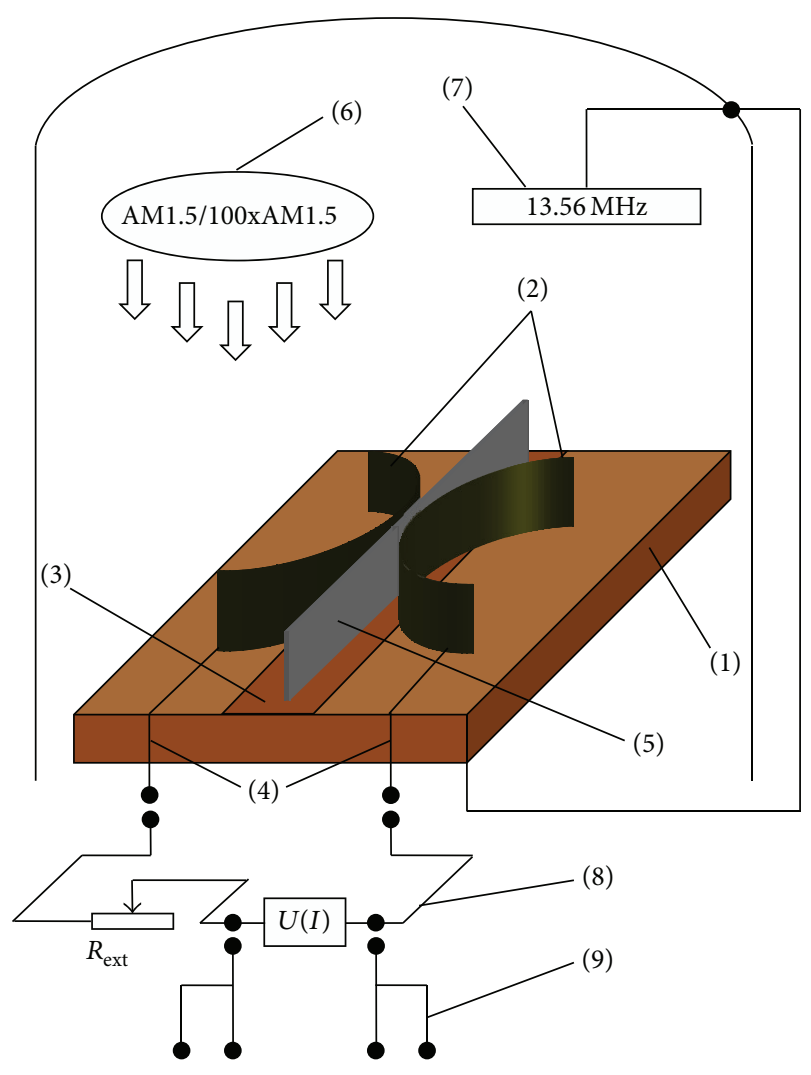

FIGURE 1: Schematic view of the holder and the setup for treatments and measurements: (1) - base; (2) - beryllium-copper springs; (3) isolator template; (4)- Ag contacts for measurement of $I-U$ characteristics; (5) - a single SC with VA p-n junction; (6) - imitators of solar irradiation; (7) - upper electrode for vacuum PECVD method; (8) -loaded $I-U$ setup; and (9)—compensating $I-U$ setup.

power ranged from $100 \mathrm{~W}$ to $250 \mathrm{~W}$ (the anode diameter was $13 \mathrm{~cm}$ ). The concentration of nitrogen in the Ar: $\mathrm{CH}_{4}: \mathrm{H}_{2}: \mathrm{N}_{2}$ mixture for generation of the plasma varied from $10 \%$ to $45 \%$. The pressure in the chamber was fixed of 0.2 torr. During the deposition, the RF bias voltage was fixed at the substrate $(1900 \mathrm{~V})$; deposition was made at room temperature of the holder [11-13]. The refractive index, absorption coefficient, and thickness of DLCFs were determined with a laser ellipsometer (wavelength $\lambda=632 \mathrm{~nm}$ ) at the incidence angle of $10^{\circ}$. In the course of plasma treatment, the holder and contacts were protected with special masks to prevent both solder sputtering and addition of contaminations into the anodecathode space from the contacts.

ARC was deposited on the front side of the samples only to compare its influence on the changes of the parameters of SCs. The optimum thicknesses of ARCs were determined from the value of refractive index as was described in [8]: $d_{\text {film }} \approx \lambda / 4 n_{\text {film }}, n_{\text {film }} \approx \sqrt{n_{0} n_{\text {sub }}}$, where $n_{0}, n_{\text {sub }}$, and $n_{\text {film }}$ are the refractive indices of the air-film interface $\left(n_{0}=1\right)$, substrate $\left(\mathrm{Si}, n_{\text {sub }}=3.96\right)$, and the DLCF, respectively. In such a way, the value of DLCF refractive index was optimized to reach the minimum reflection. And the corresponding values of thickness and refractive index are $70 \mathrm{~nm}$ (at $\lambda=632 \mathrm{~nm}$ ) and 2.0 , respectively. 
Reactive ion etching (RIE) was performed with PlasmaLab 80 system by using a mixture of $\mathrm{CF}_{6}$ and inert gases to decrease the thickness of SCs by $100 \mu \mathrm{m}$.

A double-beam Shimadzu UV-VIS-NIR-3600 spectrophotometer equipped with an integrating sphere ISR-3100 was applied to measure the spectra of diffuse reflection at a normal incidence of light. Because of the large size and specific shape of the module, the optical spectra were measured using a manually designed setup. In such a way normal incidence specular reflection of MJ Si-SC modules (both initial and those after plasma treatments) was measured in a few places on the surface of the module and was averaged. The illumination light beam spot from a tungsten lamp after chopper and prism monochromator had the $10 \mathrm{~mm} \times 4 \mathrm{~mm}$. This spot was directed on the central part of samples to uniformly illuminate all the stripes in a stack and thus maintain generation of photocurrent. A signal from the load passed through the lock-in amplifier and was measured. The regime of short-circuit photocurrent was maintained during the measurements. The photocurrent yield was obtained with the help of a calibrated photodetector (S1227-1010BQ diode, Hamamatsu).

Both light and dark $I-U$ curves of SJ as well as MJ SCs were measured with a Keithley-2410H SMU. This setup is shown in Figure 1. The light $I-U$ curves of Si-SCs under AM1.5 conditions were obtained with a compensating technique using an external power source. This enabled us to compare the dark and light $I-U$ curves and simulate them to extract the additional parameters depending on the treatment conditions. It should be noted that in such a way high $U_{\mathrm{OC}}$ becomes understated by $15 \%$ to avoid destruction of elements during the $I-U$ measurements. The collected results were extrapolated by using the regression method. The load $I-U$ characteristics, both under AM1.5 and 100AM1.5 conditions, were measured with a RIGOL DS1064B oscilloscope under the calibrated pulsed flash light.

\section{Results and Discussion}

The images of the surfaces of SCs taken before and after plasma treatments and deposition of DLCFs are presented in Figure 2. The surface patterns of SJ taken after mechanical polishing with diamond paste are shown in Figure 2(a). One can see that there are traces of saw cuts on the edges of the sample surfaces. After mechanical cutting, subsequent surface polishing was done with hydrogen- and argon-containing plasma treatments. Next, hydrogen plasma treatment was done with subsequent immediate DLCF deposition. One can estimate that the surface roughness (Figure 2(b)) was slightly reduced after plasma etching and DLCF deposition (Figure 2(c)).

After trimming and polishing of silicon, a damaged layer (with cracks) was formed within the surface area. A depth of this layer varied from $5 \mu \mathrm{m}$ to $15 \mu \mathrm{m}$, and the elastic deformation zone may extend to a considerable depth from $50 \mu \mathrm{m}$ to $150 \mu \mathrm{m}$. This may result in the accumulation of a large number of traps; those are recombination-active centers (bulk and surface).
Due to the traps and recombination centers, the reverse current was increased as can be seen from Figure 3(a), curve 1 (shunt resistance was increased after treatment, $R_{\mathrm{sh}}$ (int) is $42 \mathrm{kOhm}$, and $R_{\mathrm{sh}}$ (DLC) is $94 \mathrm{kOhm}$ ), and this consequently resulted in the drops of short-circuit current $I_{\mathrm{SC}}$ and opencircuit voltage $U_{\mathrm{OC}}$. The light $I-U$ characteristics of SJ Si-SCs are presented in Figure 3(b). All the results are summarized in Table 1 according to the plasma treatments.

It is demonstrated that all the treatments made slightly improved the parameters of SCs. In particular, plasma treatment is a cause of the increase of $I_{\mathrm{SC}}$ (Table 1). This can be explained by the fact that hydrogen atoms passivate the recombination-active centers such as silicon dangling bonds. Argon plasma, in its turn, slightly removes the damaged upper layer due to the higher atom mass with respect to hydrogen atom and provides uniformity of surface roughness. It was determined that the most efficient treatments that made it possible to achieve the best values of SCs parameters were plasma treatments with hydrogen and argon ions. Treatment in argon plasma with subsequent hydrogen plasma treatment resulted in the improvement of $U_{\mathrm{OC}}$ and fill factor (FF). Similar effect was observed after the deposition of DLCFs. As expected, the highest $I_{\mathrm{SC}}$ value was observed due to the ARC effect. Thus, we assume that the value of shunt resistance was increased after the treatments due to passivation effect. The values of series resistance were decreased mainly due to the reduction of internal mechanical stresses within interfaces and the improvement of Schottky contact owing to RF treatment. To summarize, we conclude that the combination of procedures described above results in growth of efficiency $(\eta)$ of SJ-SCs by up to 1.6 times (Table 1 ). It should be noted that all the processes cannot completely remove the broken layer and elastic strain in the SCs. After module assembling, cracks or dislocations are formed that can pass throughout the SC. Therefore, additional processes should be applied for the removal of the broken layer and improvement of SCs characteristics.

Next we applied optimal regimes for the treatments and deposition of DLC coating to improve the parameters of completely built modules. The light $I-U$ characteristics of $\mathrm{MJ} \mathrm{Si-}$ SC-s are shown in Figure 4(a). The loaded $I-U$ characteristics (both at AM1.5 and 100AM1.5) taken under assistance of a calibrated solar imitator are shown in Figure 4(b) and inset, respectively. The corresponding results are summarized in Table 2.

Curve 2 differs from curve 1 (see Figure 4(a)) mainly due to the higher value of FF (0.734 rather than 0.538), higher value of $R_{\mathrm{sh}}$, and smaller value of $R_{s}$. Unfortunately, the value of $I_{\mathrm{SC}}$ did not change after treatments. We assume that this current flow was blocked in the damaged layer formed in the course of assembling and mechanical treatment. The curves presented in Figure 4(b) and inset were collected with the help of the loading technique and do not differ significantly from the similar curves in Figure 4(a). The curves obtained under 100AM1.5 are characterized by the highest $U_{\mathrm{OC}}$ almost equal to $16.6 \mathrm{~V}$. But the damaged layer in this sample also limits the current flow through the module. The normal incidence diffuse reflection spectra for the VA-MJ-p-n-Si-SC modules (both initial and those after plasma treatments 
TABLE 1: The specific parameters of single element of a SC with vertically aligned p-n junction obtained by the compensated technique.

\begin{tabular}{|c|c|c|c|c|}
\hline Parameters & $\begin{array}{c}\text { Initial AM1.5 } \\
\text { (compensated) }\end{array}$ & $\mathrm{H}^{+} 5$ min & $\mathrm{H}^{+} 5 \min +\mathrm{Ar}^{+} 5 \mathrm{~min}$ & $\mathrm{H}^{+} 5 \mathrm{~min}+\mathrm{Ar}^{+} 5 \mathrm{~min}+\mathrm{H}^{+} 5 \mathrm{~min}+\mathrm{DLC} 70 \mathrm{~nm}$ \\
\hline $\begin{array}{l}I_{\mathrm{SC}} / I_{\mathrm{SC} 0} \text {, } \\
\text { short-circuit current }\end{array}$ & 1 & 1.19 & 1.26 & 1.42 \\
\hline $\begin{array}{l}U_{\mathrm{OC}} / U_{\mathrm{OC} 0} \\
\text { open-circuit voltage }\end{array}$ & 1 & 1 & 1.04 & 1.08 \\
\hline $\begin{array}{l}\mathrm{FF} / \mathrm{FF}_{0} \\
\text { fill factor }\end{array}$ & 1 & 0.97 & 1.02 & 1.05 \\
\hline $\begin{array}{l}\eta / \eta_{0} \\
\text { efficiency }\end{array}$ & 1 & 1.15 & 1.34 & 1.6 \\
\hline $\begin{array}{l}R_{s} / R_{s 0}, \\
\text { series resistance }\end{array}$ & 1 & 0.8 & 0.77 & 0.73 \\
\hline $\begin{array}{l}R_{\mathrm{sh}} / R_{\mathrm{sh} 0} \\
\text { shunt resistance* }\end{array}$ & 1 & 1.3 & 0.5 & 2 \\
\hline
\end{tabular}

*Values of the resistances were estimated from the light $I-U$ characteristics.

TABLE 2: Parameters of multijunction SCs cells under light illumination.

\begin{tabular}{|c|c|c|c|c|c|}
\hline Treatments & $S, \mathrm{~cm}^{2}$ & $I_{\mathrm{SC}}, \mathrm{mA}$ & $U_{\mathrm{OC}}, \mathrm{V}$ & $\eta, \%$ & FF \\
\hline AM1.5 (compensated), initial & 6 & 0.91 & 11.76 & 0.954 & 0.538 \\
\hline AM1.5 (compensated), DLC $70 \mathrm{~nm}$ & 6 & 0.918 & 11.72 & 1.32 & 0.734 \\
\hline RIE & 6 & 9.69 & 11.86 & 10.12 & 0.53 \\
\hline $\mathrm{RIE}+\mathrm{RF}$ & 6 & 10.12 & 11.87 & 12.61 & 0.63 \\
\hline AM1.5 (loaded), DLC $70 \mathrm{~nm}$ & 6 & 0.912 & 11.71 & 1.31 & 0.736 \\
\hline 100AM1.5 (loaded, pulse), DLC $70 \mathrm{~nm}$ & 6 & 99.06 & 16.61 & 2.1 & 0.75 \\
\hline
\end{tabular}

and DLCF deposition) were obtained with a double-beam spectrophotometer equipped with integrating sphere and are presented in Figure 5. In the inset we demonstrate the normal incidence specular reflection spectra of the modules.

One can see from Figure 5 that some mismatch in values of the reflectance is observed when comparing the corresponding curves. We assume that the results obtained by using the single-beam specular reflection technique (even with less accuracy) were more correct than those obtained with the diffuse reflection setup due to uniform illumination. Curve 1 differs from curves 2 and 3 by less than $10 \%$ within the visible range only. This can be explained by the fact that back side of the sample (corresponding to curve 2) was not affected by direct etching with plasma components, and only the influence of RF irradiation was responsible for the reflectivity decrease. The position of curve 3 corresponding to the reflection spectrum from the front side of the modules was shifted down mainly due to the increase of surface roughness after plasma etching. The two peaks in the UV side of the spectrum may be attributed to the allowed direct optical transition in Si bulk. Those peaks are not observed in curve 4 . We assume that this may be due to the presence of DLCF that not only serves as ARC (reducing reflection by about $50 \%$ ) but also absorbs UV light with photon energy higher than the film optical bandgap. To explain the changes in module efficiency after the plasma treatments, let us analyze the behavior of the photocurrent. To this end, we discuss the well-known two-diode model for the simulation of the $I-U$ characteristics of double-sided VA-MJ-p-n-Si-SCs which is depicted in Figure 6(a) following [14]. The equation describing the output current of the SC can be written as follows:

$$
I=I_{\mathrm{PV}}-\sum_{i=1}^{2} I_{0 i}\left[\exp \left(\frac{U+I R_{s}}{a_{i} V_{T i}}\right)-1\right]-\left(\frac{U+I R_{s}}{R_{\mathrm{sh}}}\right),
$$

where $I_{\mathrm{PV}}$ is photogenerated current, $I_{01}$ and $I_{02}$ are the reverse saturation currents of diode 1 and diode 2 , respectively, and $V_{T 1}$ and $V_{T 2}$ are thermal voltages. The components $a_{1}$ and $a_{2}$ represent here the diode ideality factor, and sometimes it should be assumed that $a_{1}=1$ and $a_{2}=2$.

Simulation of the $I-U$ curve by using this model requires computation of seven parameters $\left(I_{\mathrm{PV}}, I_{01}, I_{02}, R_{p}, R_{s}, a_{1}\right.$, and $a_{2}$ ), and then $I_{01}, I_{02}, R_{\mathrm{sh}}$, and $R_{s}$ can be obtained using various methods, for example, by iteration [15]:

$$
\begin{aligned}
I= & I 1_{\mathrm{PV}}+I 2_{\mathrm{PV}}-\sum_{i=1}^{5} I_{0 i}\left[\exp \left(\frac{U+I R_{s}}{a_{i} V_{\mathrm{Ti}}}\right)-1\right] \\
& -\left(\frac{U+I R_{s}}{R_{\mathrm{sh}}}\right),
\end{aligned}
$$

where $I 2_{\mathrm{PV}}$ is photogenerated current from the back side of SC and $I_{03}$ is the reverse saturation currents of blocking diode 3 (middle one).

An analysis of the model permits us to assume that current flow through the vertical p-n junctions may be limited by module thickness. This increases the losses in the shunt diode (third diode) when this diode is partially or not illuminated. The condition at which diode is not illuminated is realized 


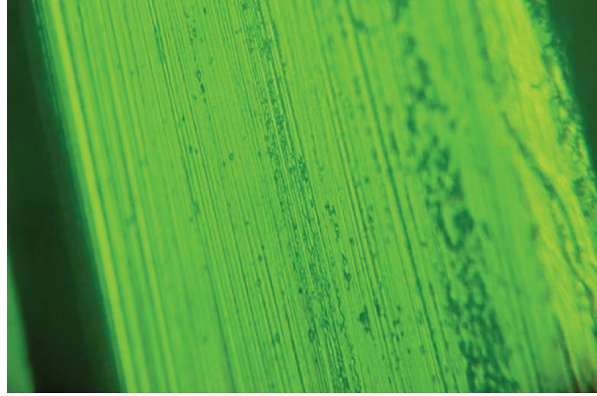

(a)

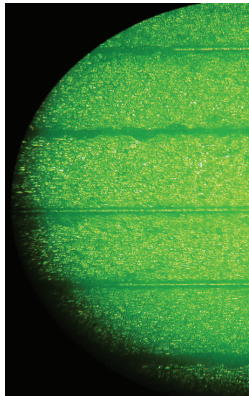

(b)

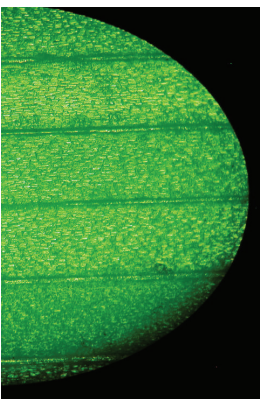

(c)

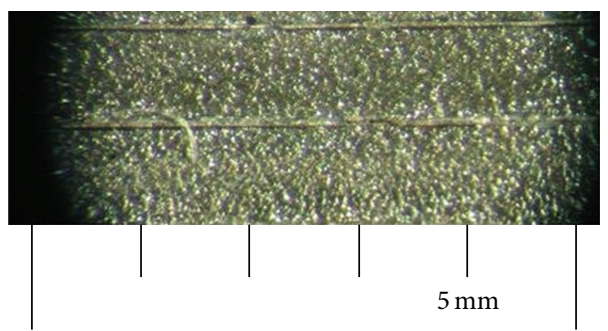

(d)

FIGURE 2: Images of the surface of Si-SC with VA p-n junction under 500x magnification. (a) after mechanical processing; (b) after RF treatments; (c) after RF treatments and DLCF coating; and (d) surface patterns of module.

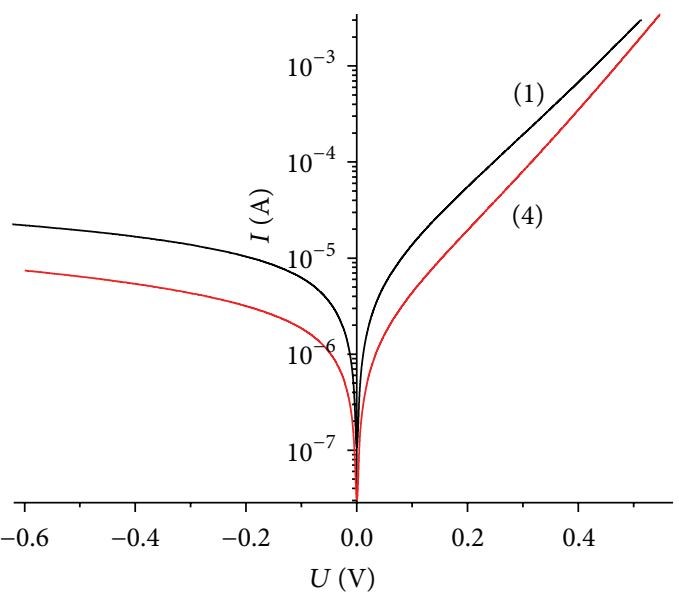

(a)

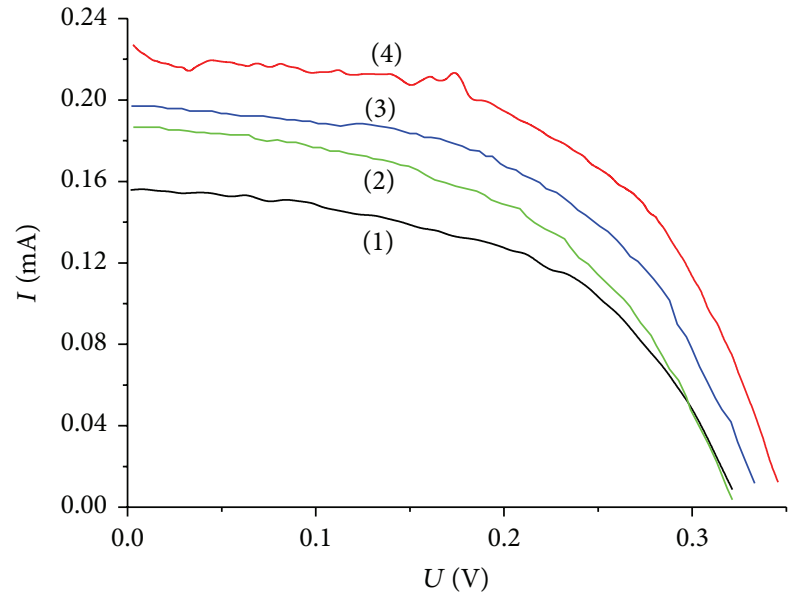

(b)

FIGURE 3: I-U characteristics of SJ Si-SC with VA p-n junction in the darkness (a) and under light illumination (b) for (1) - initial; (2)—after $\mathrm{H}^{+}$plasma etching for $5 \mathrm{~min}$; (3)-(2) $+\mathrm{Ar}^{+}+\mathrm{H}^{+}$; and (4)-(3) + DLC coating. The conditions of DLCF deposition are $P=175 \mathrm{~W}, N=20 \%$, and $t=4 \mathrm{~min}$. The conditions of illumination are $P=100 \mathrm{~mW} / \mathrm{cm}^{2}$ and $S=0.03 \mathrm{~cm}^{2}$.

when thickness of SC is too high. The sample thickness is $300 \mu \mathrm{m}$ which is too high for light penetration according to the absorption coefficient of silicon in the case of a doublesided SC.

It is known that absorption depth in silicon ranges from $100 \mathrm{~nm}$ at $\lambda=0.4 \mu \mathrm{m}$ to $100 \mu \mathrm{m}$ at $\lambda=1 \mu \mathrm{m}$. Therefore, we proposed applying RIE for removal of the upper damaged layer. One can see from Figure 7(a) that plasma-chemical etching to a depth of $100 \mu \mathrm{m}$ by RIE at first removes the damaged layer and consequently reduces elastic strains in the wafer. This results in decrease of the recombination in the bulk (the direct curve 2 is higher and the reverse curve 2 is lower). The positive effect of RIE is in the changes of $R_{\text {sh }}$ from 2.2 MOhm to 7.6 MOhm. In addition, this etching reduces thickness of the wafer, thus leading to more uniform illumination of the vertical $\mathrm{p}-\mathrm{n}$ junction and reduction of losses in the shunt diode. As was demonstrated in Figure 8(a), the initial thickness of SC before RIE was $300 \mu \mathrm{m}$ that limits propagation of the light in depth. After etching it dropped to $200 \mu \mathrm{m}$ (Figure $8(\mathrm{~b})$ ) and such value of the thickness is the minimal value for maximal absorption in $\mathrm{Si}$ in the case of a double-sided SC. 


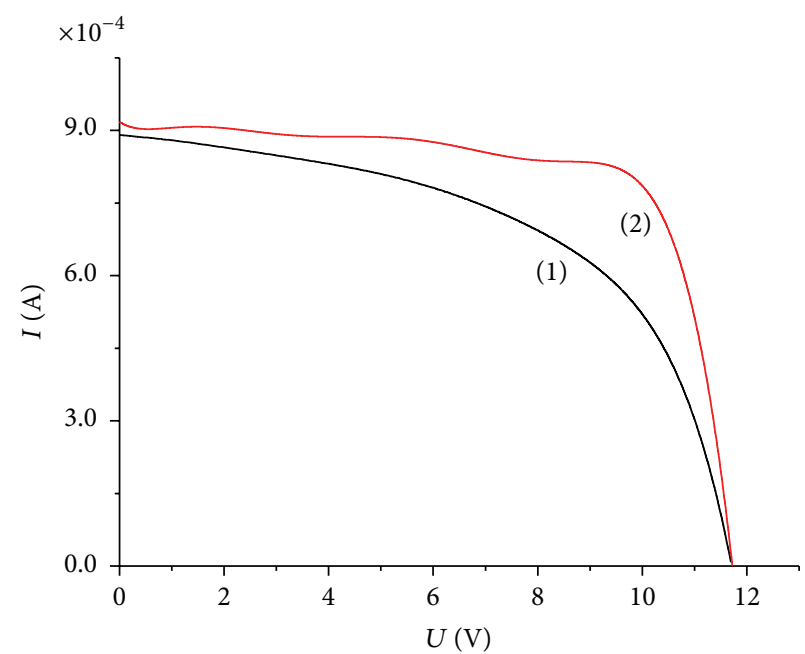

(a)

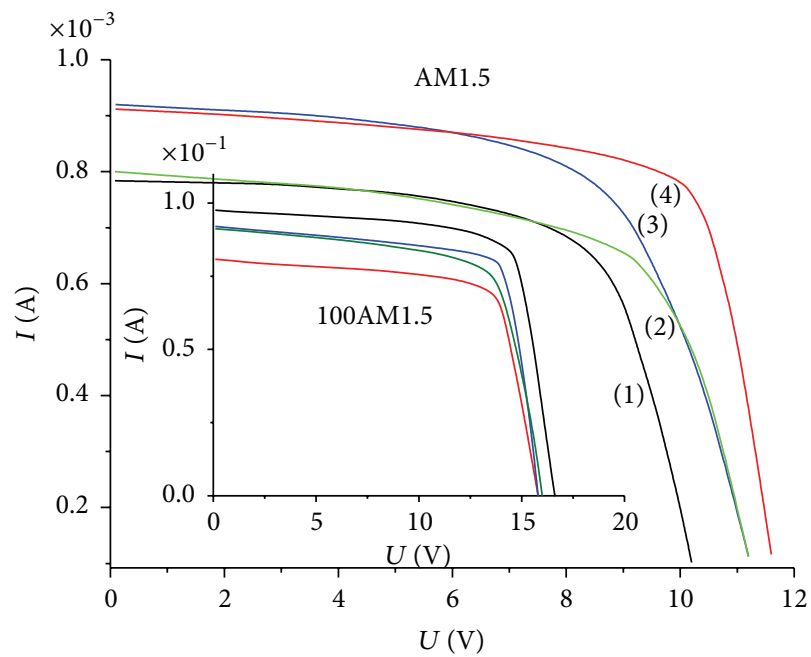

(b)

Figure 4: $I-U$ characteristics of MJ Si-SC under light illumination: (a) (1)-initial curve, (2)—with DLC coating (compensated technique); (b) $I-U$ curves obtained by loaded technique with respect to the treatments: (1) - initial; (2) - after $\mathrm{H}^{+}$plasma etching for 5 min; (3) - (2) $+\mathrm{Ar}^{+}+\mathrm{H}^{+}$; and (4)-(3) + DLCF sputtering. Inset: $I-U$ curves (treatment is (4)) obtained by pulsed flash light assisted loaded technique. Conditions of illumination: $P=100 \mathrm{~mW} / \mathrm{cm}^{2}$ (AM1.5) and pulse $P=10000 \mathrm{~mW} / \mathrm{cm}^{2}(100 \mathrm{AM} 1.5), S=6 \mathrm{~cm}^{2}$.

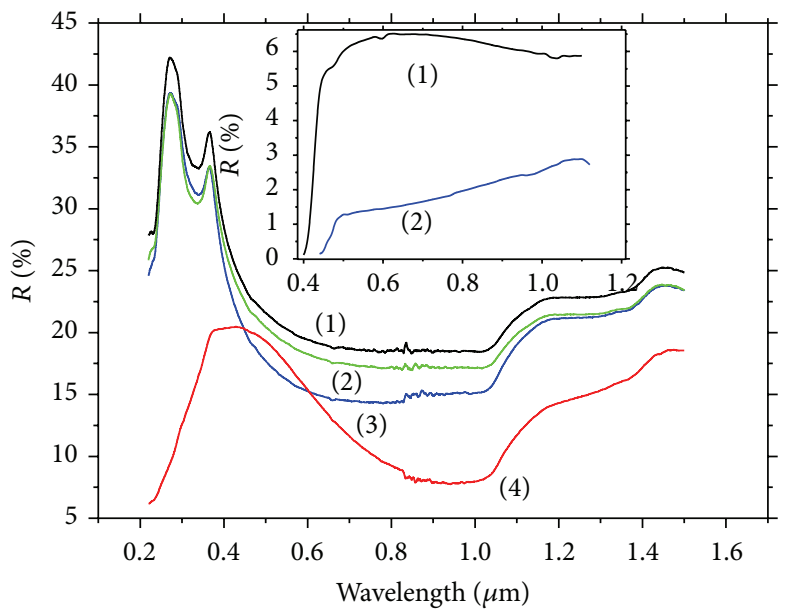

FIGURE 5: Normal incidence diffuse reflection of a set of MJ Si-SCs: (1)—initial; (2)—after RF treatments (back side of SC); (3)—after RF treatments (front side of SC); (4) - after plasma treatments and deposition of DLCF. Inset: Normal incidence specular reflection of a series of MJ Si-SCs: (1)_initial; (2) —after plasma treatments and deposition of DLCF.

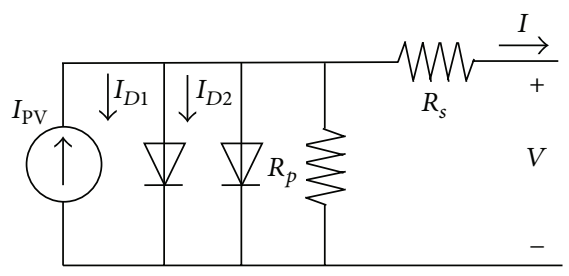

(a)
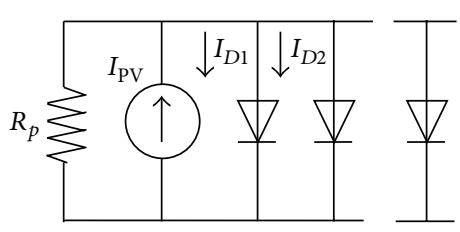

(b)

FIGURE 6: Models of c-Si-based solar cell: (a) two-diode model [14]; (b) multidiode model with vertically aligned p-n junctions. 


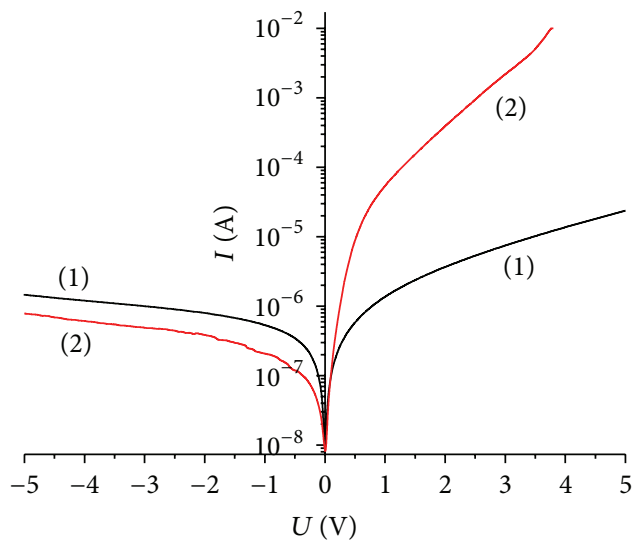

(a)

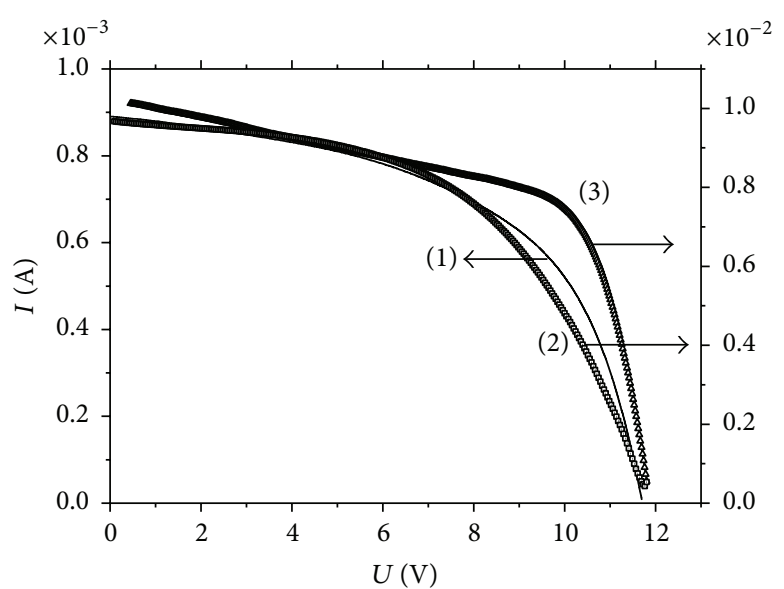

(b)

FIGURE 7: Dark (a) and light (b) I-U characteristics of MJ Si-SC: (1) —initial curve, (2)—after RIE etching; and (3)—after RIE + RF treatments.

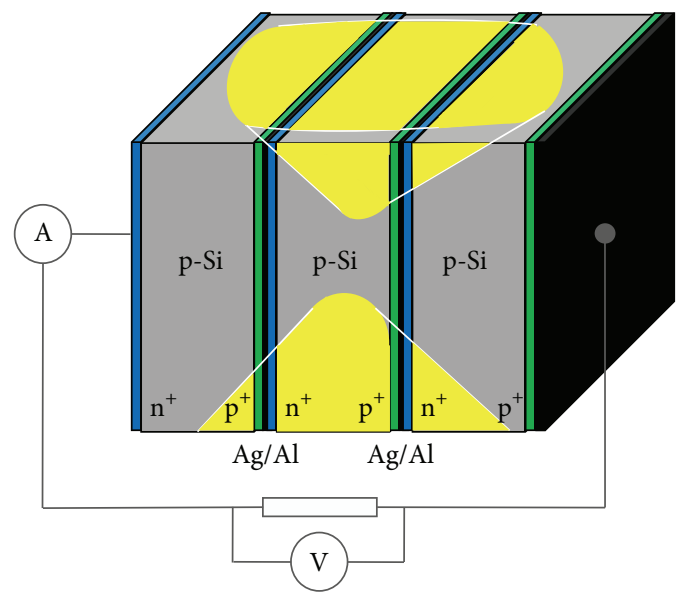

(a)

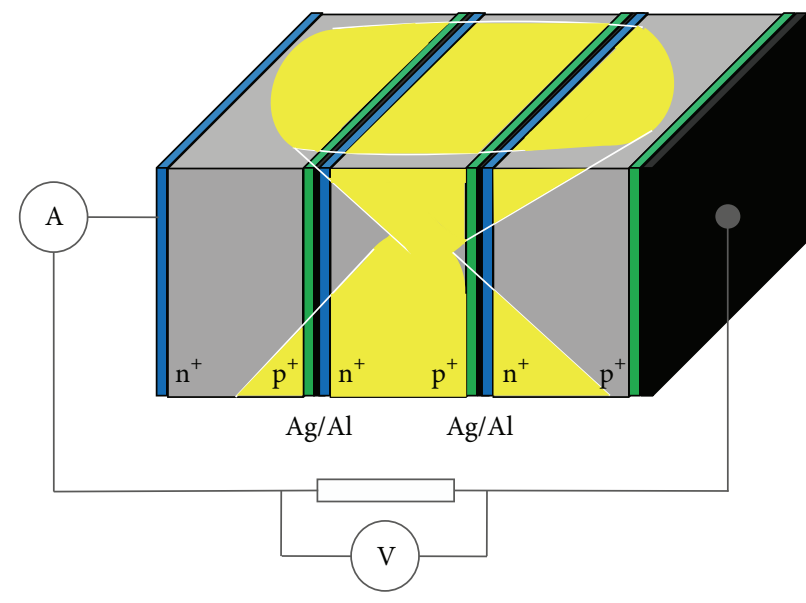

(b)

FIGURE 8: Model of multidiode solar cell module with vertically aligned p-n junctions. (a) initial; (b) after RIE and RF treatments. Light propagation regions are given in yellow.

One can see from Figure 7(b) that $I_{\mathrm{SC}}$ of curve 2 is almost 10 times higher than that of curve 1 . Such an improvement was obtained due to removal of the damaged layer by RIE etching. All the corresponding parameters are collected in Table 2. It should be noted that RIE etching does not reduce surface recombination and reflectivity. Therefore, we assume that additional treatments should slightly improve the parameters of SC. Next, in order to improve FF and efficiency of SC, hydrogen-containing plasma treatment was applied with minimum concentration of hydrogen in a gas flow at discharge power of $90 \mathrm{~W}$. One can see from Figure 7(b) that FF for curve 3 was improved by almost 15\% after RIE etching. This results in efficiency growth up to $12.61 \%$.

\section{Conclusions}

The design and fabrication of special holders were made to measure the current-voltage characteristics and fix miniature SCs. Plasma treatments and subsequent deposition of DLCFs on the working surfaces of Si-based SCs with vertically aligned $\mathrm{p}-\mathrm{n}$ junction and modules were performed. The designed photovoltaic modules were composed of 25 single $300 \mu \mathrm{m}$ subcells with total area of $6 \mathrm{~cm}^{2}$. The generated voltage was almost $12 \mathrm{~V}$ and higher than $16 \mathrm{~V}$ at $100 \mathrm{AM} 1.5$ illumination conditions. Such high value of generated voltage as well as possibility to use both sides of modules enables adjusting these modules directly for the applications in the electronic conversion systems.

The procedure of SCs surfaces passivation by plasma treatments is discussed. It is demonstrated that hydrogen plasma treatment enables improving the characteristics of VA-MJ-p-n-Si-SCs by passivation of recombination-active centers. It was suggested to use additional processing in argon plasma prior to the hydrogen treatment. This RF ionplasma etching slightly removes the upper damaged layer, and subsequent deposition of DLCFs on the working surfaces provides the improvement of the efficiency of SC by up to $60 \%$. Plasma-chemical etching to a depth of $100 \mu \mathrm{m}$ using the 
RIE technique removes the broken layer and consequently reduces the elastic strain in the wafer, thus resulting in decrease of the recombination in the bulk and increase of the efficiency of SC by up to 12 times.

\section{Competing Interests}

The authors declare that there is no conflict of interests regarding the publication of this paper.

\section{Acknowledgments}

This work was supported by the National Long-term Project no. WQ20142200205 “Thousand Talents Plan of Bureau of Foreign Experts Affairs” of the People's Republic of China.

\section{References}

[1] T. M. Razykov, C. S. Ferekides, D. Morel, E. Stefanakos, H. S. Ullal, and H. M. Upadhyaya, "Solar photovoltaic electricity: current status and future prospects," Solar Energy, vol. 85, no. 8, pp. 1580-1608, 2011.

[2] E. G. Guk, N. S. Zimogorova, M. Z. Shvartz, and V. B. Shuman, "Multiple-junction silicon concentrator solar cells fabricated by diffusion bonding," Technical Physics, vol. 42, no. 2, pp. 238-240, 1997.

[3] E. G. Guk, T. A. Nalet, M. Z. Shvarts, and V. B. Shuman, "Characteristic features of silicon multijunction solar cells with vertical p-n junctions," Semiconductors, vol. 31, no. 7, pp. 726-727, 1997.

[4] V. R. Kopach, M. V. Kirichenko, S. V. Shramko, R. V. Zaitsev, and S. A. Bondarenko, "New approach to the efficiency increase problem for multi-junction silicon photovoltaic converters with vertical diode cells," Functional Materials, vol. 15, no. 2, pp. 253-258, 2008, http://www.isc.kharkov.com/journal/contents/ 15-2/fm152-11.pdf.

[5] C. Strümpel, M. McCann, G. Beaucarne et al., "Modifying the solar spectrum to enhance silicon solar cell efficiency-an overview of available materials," Solar Energy Materials and Solar Cells, vol. 91, no. 4, pp. 238-249, 2007.

[6] B. M. Kayes, H. A. Atwater, and N. S. Lewis, "Comparison of the device physics principles of planar and radial p-n junction nanorod solar cells," Journal of Applied Physics, vol. 97, no. 11, Article ID 114302, 2005.

[7] X. Zhang, C. W. Pinion, J. D. Christesen, C. J. Flynn, T. A. Celano, and J. F. Cahoon, "Horizontal silicon nanowires with radial p-n junctions: a platform for unconventional solar cells," Journal of Physical Chemistry Letters, vol. 4, no. 12, pp. 20022009, 2013.

[8] J. Zhao and M. A. Green, "Optimized antireflection coatings for high-efficiency silicon solar cells," IEEE Transactions on Electron Devices, vol. 38, no. 8, pp. 1925-1934, 1991.

[9] M. H. Oliveira Jr., D. S. Silva, A. D. S. Côrtes, M. A. B. Namani, and F. C. Marques, "Diamond like carbon used as antireflective coating on crystalline silicon solar cells," Diamond \& Related Materials, vol. 18, no. 5-8, pp. 1028-1030, 2009.

[10] A. Tamulevičiene, Š. Meškinis, V. Kopustinskas, and S. Tamulevičius, "Diamond like carbon film as potential antireflective coating for silicon solar cells," Medziagotyra, vol. 16, no. 2, pp. 103-107, 2010.

[11] N. I. Klyui, V. G. Litovchenko, A. N. Lukyanov et al., "Optical and mechanical properties of nitrogen-doped diamond-like carbon films," Ukrainian Journal of Physics, vol. 51, no. 7, pp. 710$714,2006$.

[12] N. I. Klyui, V. P. Kostylyov, V. G. Lytovchenko, A. N. Lukyanov, V. V. Chernenko, and V. I. Khivrych, "Influence of $\gamma$-irradiation on the parameters of silicon-based solar cells," Ukrainian Journal of Physics, vol. 52, no. 3, pp. 245-250, 2007.

[13] N. I. Klyui, V. G. Litovchenko, I. P. Lisovsky et al., "Effect of $\mathrm{UV}$ and $\gamma$-irradiation on the structure and optical properties of $\alpha$-C:H:N films," Ukrainian Journal of Physics, vol. 56, no. 5, pp. 462-466, 2011.

[14] C.-T. Sah, R. N. Noyce, and W. Shockley, "Carrier generation and recombination in $\mathrm{p}-\mathrm{n}$ junctions and $\mathrm{p}-\mathrm{n}$ junction characteristics," Proceedings of the IRE, vol. 45, no. 9, pp. 1228-1243, 1957.

[15] K. Ishaque, Z. Salam, and H. Taheri, "Simple, fast and accurate two-diode model for photovoltaic modules," Solar Energy Materials and Solar Cells, vol. 95, no. 2, pp. 586-594, 2011. 

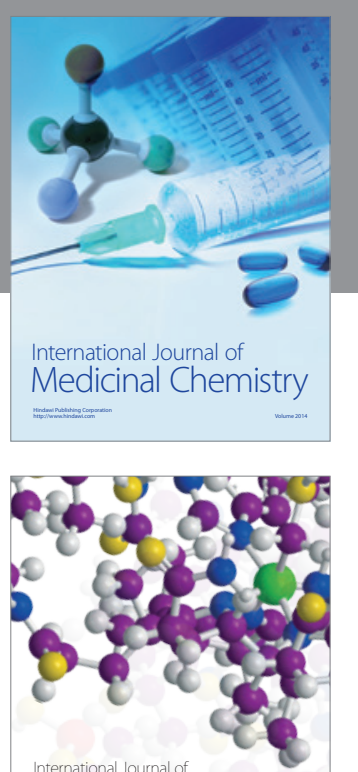

Carbohydrate Chemistry

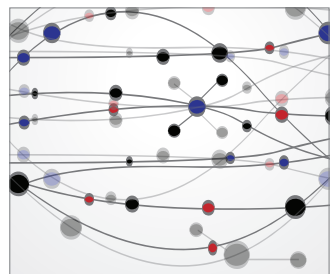

The Scientific World Journal
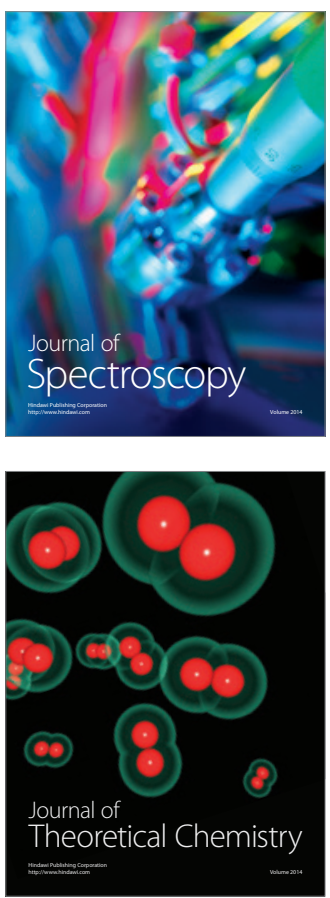
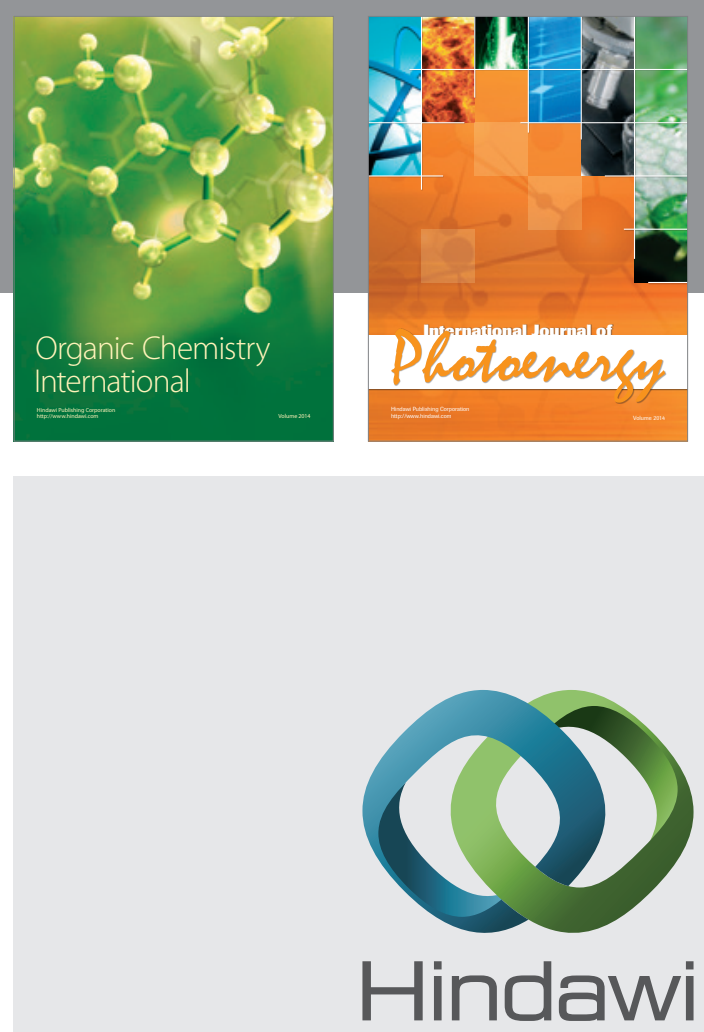

Submit your manuscripts at

http://www.hindawi.com

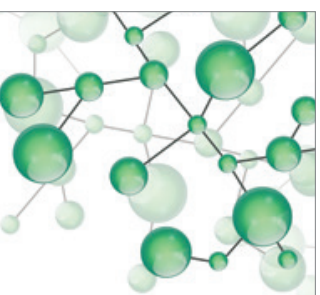

International Journal of

Inorganic Chemistry

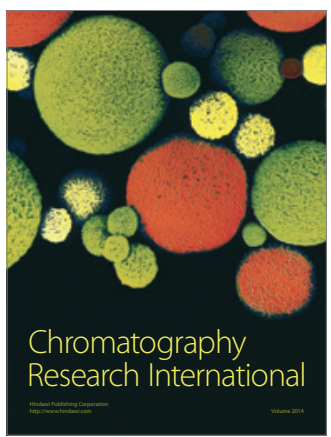

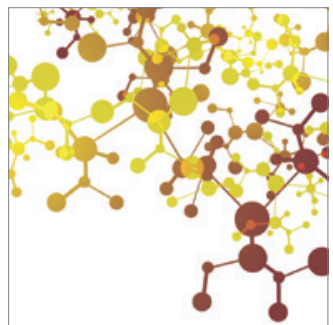

Applied Chemistry
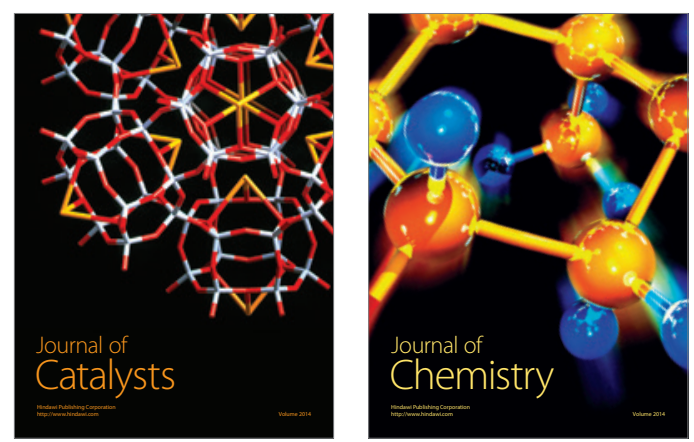
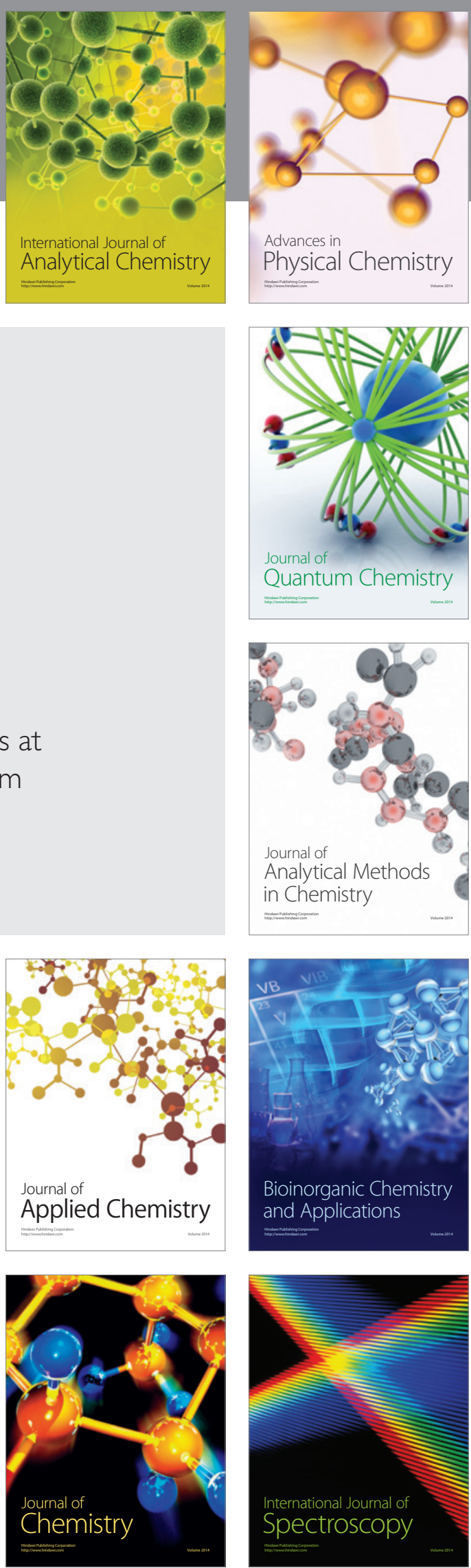